\title{
Corrigendum
}

\section{Corrigendum to “Derivation of Diagonally Implicit Block Backward Differentiation Formulas for Solving Stiff Initial Value Problems"}

\author{
Iskandar Shah Mohd Zawawi, ${ }^{1}$ Zarina Bibi Ibrahim, ${ }^{1,2}$ and Khairil Iskandar Othman ${ }^{3}$ \\ ${ }^{1}$ Department of Mathematics, Faculty of Science, Universiti Putra Malaysia, 43400 Serdang, Selangor, Malaysia \\ ${ }^{2}$ Institute for Mathematical Research, Universiti Putra Malaysia, 43400 Serdang, Selangor, Malaysia \\ ${ }^{3}$ Department of Mathematics, Faculty of Computer and Mathematical Sciences, Universiti Teknologi MARA, \\ 40450 Shah Alam, Selangor, Malaysia
}

Correspondence should be addressed to Zarina Bibi Ibrahim; zarinabb@upm.edu.my

Received 23 August 2017; Accepted 4 October 2017; Published 5 November 2017

Copyright (c) 2017 Iskandar Shah Mohd Zawawi et al. This is an open access article distributed under the Creative Commons Attribution License, which permits unrestricted use, distribution, and reproduction in any medium, provided the original work is properly cited.

In the article titled "Derivation of Diagonally Implicit Block Backward Differentiation Formulas for Solving Stiff Initial Value Problems," [1] there are misreported information and typing errors that are corrected as follows.

In the fourth paragraph of the "Introduction" section, the sentence "The following equations represent the formulas of fully implicit 2-point block backward differentiation formulas of order three (FI2BBDF(3)) and fully implicit 3-point block backward differentiation formula of order three (FI3BBDF(3))" should be corrected to "The following equations represent the formulas of fully implicit 2point block backward differentiation formulas of order three (FI2BBDF(3)) and fully implicit 3-point block backward differentiation formula of order five (FI3BBDF(5))." Accordingly, equation (4) should be written as follows:

$F I 3 B B D F(5)$. One has

$$
\begin{aligned}
y_{n+1}= & \frac{1}{10} y_{n-2}-\frac{3}{4} y_{n-1}+3 y_{n}-\frac{3}{2} y_{n+2}+\frac{3}{20} y_{n+3} \\
& +3 h f_{n+1}, \\
y_{n+2}= & -\frac{3}{65} y_{n-2}+\frac{4}{13} y_{n-1}-\frac{12}{13} y_{n}+\frac{24}{13} y_{n+1}-\frac{12}{65} y_{n+3} \\
& +\frac{12}{13} h f_{n+2},
\end{aligned}
$$

$$
\begin{aligned}
y_{n+3}= & \frac{12}{137} y_{n-2}-\frac{75}{137} y_{n-1}+\frac{200}{137} y_{n}-\frac{300}{137} y_{n+1} \\
& +\frac{300}{137} y_{n+2}+\frac{60}{137} h f_{n+3} .
\end{aligned}
$$

In the fifth paragraph of the "Introduction" section, the sentence "The formulas of fully implicit 2-point block extended backward differentiation formula of order three (FI2BEBDF(3)) and fully implicit 3-point block extended backward differentiation formula of order three (FI3BEBDF(3)) are given in the following forms" should be corrected to "The formulas of fully implicit 2-point block extended backward differentiation formula of order four (FI2BEBDF(4)) and fully implicit 3-point block extended backward differentiation formula of order six (FI3BEBDF(6)) are given in the following forms." Accordingly, equation (5) shows the "FI2BEBDF(4)" not "FI2BEBDF(3)." Moreover, equation (6) should be written as follows:

FI3BEBDF(6). One has

$$
\begin{aligned}
y_{n+1}= & -\frac{1}{80} y_{n-2}+\frac{1}{8} y_{n-1}-\frac{3}{4} y_{n}+\frac{25}{16} y_{n+2}+\frac{3}{40} y_{n+3} \\
& -\frac{3}{2} h f_{n+1}-\frac{3}{4} h f_{n+2},
\end{aligned}
$$




$$
\begin{aligned}
y_{n+2}= & -\frac{3}{25} y_{n-2}+y_{n-1}-4 y_{n}+12 y_{n+1}-\frac{197}{25} y_{n+3} \\
& +12 h f_{n+2}+\frac{12}{5} h f_{n+3}, \\
y_{n+3}= & \frac{394}{14919} y_{n-2}-\frac{2925}{14919} y_{n-1}+\frac{9600}{14919} y_{n} \\
& -\frac{18700}{14919} y_{n+1}+\frac{26550}{14919} y_{n+2}+\frac{8820}{14919} h f_{n+3} \\
& -\frac{600}{14919} h f_{n+4} .
\end{aligned}
$$

In "Numerical Results" section, the sentence "Tables 1 and 2 present the performance comparison of $\operatorname{DI} 2 \operatorname{BBDF}(2)$, $\operatorname{DI} 2 \operatorname{BBDF}(3)$, and $\operatorname{DI} 2 \mathrm{BBDF}(4)$ with $\mathrm{FI} 2 \mathrm{BBDF}(3)$ and FI2BEBDF(3), whereas Tables 3-6 exhibit the comparison of proposed methods with FI3BBDF(3) and FI3BEBDF(3)" should be changed to "Tables 1 and 2 present the performance comparison of DI2BBDF(2), DI2BBDF(3), and DI2BBDF(4) with FI2BBDF(3) and FI2BEBDF(4), whereas Tables 3-6 exhibit the comparison of proposed methods with FI3BBDF(5) and FI3BEBDF(5)." Moreover, the notations used in Tables 1-6 are updated as follows:

$h$ : step size

MAXE: maximum error

TIME: time execution using high performance computer (HPC)

DI2BBDF(2): diagonally implicit 2-point block backward differentiation formulas of order 2

DI2BBDF(3): diagonally implicit 2-point block backward differentiation formulas of order 3

DI2BBDF(4): diagonally implicit 2-point block backward differentiation formulas of order 4

FI2BBDF(3): fully implicit 2-point block backward differentiation formulas of order 3

FI2BEBDF(4): fully implicit 2-point block extended backward differentiation formulas of order 4

FI3BBDF(5): fully implicit 3-point block backward differentiation formulas of order 5

FI3BEBDF(6): fully implicit 3-point block extended backward differentiation formulas of order 6 .

Therefore, you can find the corrected versions of Tables 1 , 2, 3, 4, 5, and 6. Moreover the keys of Figures 5, 6, 7, 8, 9, and 10 should be modified as shown in Tables 1, 2, 3, 4, 5, and 6 and Figures 5, 6, 7, 8, 9, and 10.

In the "Discussion" section, there are corrections in the subsections "Maximum Error" and "Computational Time" explained below.

In subsection "Maximum Error," the sentence "Among the methods of order three, $\operatorname{DI} 2 \mathrm{BBDF}(3)$ is more accurate compared with FI2BBDF(3), FI3BBDF(3), FI2BEBDF(3), and
TABLE 1: The accuracy for Problem 1.

\begin{tabular}{lccc}
\hline$h$ & Methods & MAXE & TIME \\
\hline \multirow{4}{*}{$10^{-2}$} & FI2BBDF(3) & $5.67155 E-2$ & $1.36773 E-3$ \\
& FI2BEBDF(4) & $5.97499 E-2$ & $1.45525 E-3$ \\
& DI2BBDF(2) & $1.10568 E-2$ & $4.72498 E-3$ \\
& DI2BBDF(3) & $1.66455 E-2$ & $4.77409 E-3$ \\
& DI2BBDF(4) & $2.16342 E-2$ & $4.83298 E-3$ \\
\hline \multirow{4}{*}{$10^{-4}$} & FI2BBDF(3) & $7.34012 E-4$ & $1.25797 E-1$ \\
& FI2BEBDF(4) & $3.23640 E-5$ & $1.36259 E-1$ \\
& DI2BBDF(2) & $1.18355 E-6$ & $1.67260 E-1$ \\
& DI2BBDF(3) & $1.73430 E-6$ & $1.69325 E-1$ \\
& DI2BBDF(4) & $2.25966 E-6$ & $1.72995 E-1$ \\
\hline \multirow{4}{*}{$10^{-6}$} & FI2BBDF(3) & $7.35741 E-6$ & $1.25700 E 1$ \\
& FI2BEBDF(4) & $3.50090 E-7$ & $1.36230 E 1$ \\
& DI2BBDF(2) & $1.18742 E-10$ & $1.49159 E 1$ \\
& DI2BBDF(3) & $1.73634 E-10$ & $1.54493 E 1$ \\
& DI2BBDF(4) & $2.26000 E-10$ & $1.54620 E 1$ \\
\hline
\end{tabular}

TABle 2: The accuracy for Problem 2.

\begin{tabular}{lccc}
\hline$h$ & Methods & MAXE & TIME \\
\hline \multirow{4}{*}{$10^{-2}$} & FI2BBDF(3) & $2.71597 E-2$ & $5.96467 E-3$ \\
& FI2BEBDF(4) & $1.49811 E-2$ & $6.61025 E-3$ \\
& DI2BBDF(2) & $4.56073 E-3$ & $1.04480 E-2$ \\
& DI2BBDF(3) & $6.86126 E-3$ & $1.08421 E-2$ \\
& DI2BBDF(4) & $8.93279 E-3$ & $1.11089 E-2$ \\
\hline \multirow{4}{*}{$10^{-4}$} & FI2BBDF(3) & $3.40437 E-4$ & $5.90430 E-1$ \\
& FI2BEBDF(4) & $2.62649 E-5$ & $6.54305 E-1$ \\
& DI2BBDF(2) & $4.85404 E-7$ & $3.73210 E-1$ \\
& DI2BBDF(3) & $7.11155 E-7$ & $3.86556 E-1$ \\
& DI2BBDF(4) & $9.26476 E-7$ & $3.87070 E-1$ \\
\hline \multirow{4}{*}{$10^{-6}$} & FI2BBDF(3) & $3.41146 E-6$ & $5.90198 E 1$ \\
& FI2BEBDF(4) & $2.44097 E-7$ & $6.54106 E 1$ \\
& DI2BBDF(2) & $4.86843 E-11$ & $3.48451 E 1$ \\
& DI2BBDF(3) & $7.11903 E-11$ & $3.60490 E 1$ \\
& DI2BBDF(4) & $9.26598 E-11$ & $3.60649 E 1$ \\
\hline
\end{tabular}

TABle 3: The accuracy for Problem 3.

\begin{tabular}{cccc}
\hline$h$ & Methods & MAXE & TIME \\
\hline \multirow{4}{*}{$10^{-2}$} & FI3BBDF(5) & $3.56692 E-2$ & $1.41642 E-3$ \\
& FI3BEBDF(6) & $1.24084 E-2$ & $3.02167 E-3$ \\
& DI2BBDF(2) & $1.17256 E-3$ & $4.48489 E-3$ \\
& DI2BBDF(3) & $1.72278 E-3$ & $4.81200 E-3$ \\
& DI2BBDF(4) & $2.25003 E-3$ & $4.85301 E-3$ \\
\hline \multirow{4}{*}{$10^{-4}$} & FI3BBDF(5) & $4.35640 E-4$ & $1.30103 E-1$ \\
& FI3BEBDF(6) & $7.06516 E-5$ & $2.08115 E-1$ \\
& DI2BBDF(2) & $1.18749 E-7$ & $1.60304 E-1$ \\
& DI2BBDF(3) & $1.73636 E-7$ & $1.77445 E-1$ \\
& DI2BBDF(4) & $2.26000 E-7$ & $1.78064 E-1$ \\
\hline \multirow{4}{*}{$10^{-6}$} & FI3BBDF(5) & $4.34625 E-6$ & $1.29775 E 1$ \\
& FI3BEBDF(6) & $7.03257 E-7$ & $2.07609 E 0$ \\
& DI2BBDF(2) & $1.24989 E-11$ & $1.50739 E 1$ \\
& DI2BBDF(3) & $1.73636 E-11$ & $1.55073 E 1$ \\
& DI2BBDF(4) & $2.25999 E-11$ & $1.60216 E 1$ \\
\hline
\end{tabular}


TABLE 4: The accuracy for Problem 4.

\begin{tabular}{lccc}
\hline$h$ & Methods & MAXE & TIME \\
\hline \multirow{4}{*}{$10^{-2}$} & FI3BBDF(5) & $6.62694 E 99$ & $7.01775 E-3$ \\
& FI3BEBDF(6) & $1.68449 E-1$ & $1.37847 E-2$ \\
& DI2BBDF(2) & $2.80830 E-1$ & $1.06871 E-2$ \\
& DI2BBDF(3) & $4.00389 E-1$ & $1.24969 E-2$ \\
& DI2BBDF(4) & $4.77342 E-1$ & $1.26502 E-2$ \\
\hline \multirow{4}{*}{$10^{-4}$} & FI3BBDF(5) & $8.45376 E-3$ & $6.76737 E-1$ \\
& FI3BEBDF(6) & $6.95725 E-3$ & $1.35671 E+0$ \\
& DI2BBDF(2) & $3.56255 E-5$ & $4.32359 E-1$ \\
& DI2BBDF(3) & $5.24241 E-5$ & $4.42599 E-1$ \\
& DI2BBDF(4) & $6.85105 E-5$ & $4.56207 E-1$ \\
\hline \multirow{4}{*}{$10^{-6}$} & FI3BBDF(5) & $8.54545 E-5$ & $6.76819 E 1$ \\
& FI3BEBDF(6) & $7.18859 E-5$ & $1.35862 E 2$ \\
& DI2BBDF(2) & $3.60130 E-9$ & $4.00010 E 1$ \\
& DI2BBDF(3) & $5.26673 E-9$ & $4.00192 E 1$ \\
& DI2BBDF(4) & $6.85529 E-9$ & $4.10322 E 1$ \\
\hline
\end{tabular}

TABle 5: The accuracy for Problem 5.

\begin{tabular}{cccc}
\hline$h$ & Methods & MAXE & TIME \\
\hline \multirow{4}{*}{$10^{-2}$} & FI3BBDF(5) & $5.25481 E-3$ & $5.78083 E-4$ \\
& FI3BEBDF(6) & $3.88475 E-3$ & $9.16583 E-4$ \\
& DI2BBDF(2) & $8.56253 E-5$ & $2.29836 E-4$ \\
& DI2BBDF(3) & $1.21629 E-4$ & $1.89066 E-4$ \\
& DI2BBDF(4) & $1.65094 E-4$ & $2.30074 E-4$ \\
\hline \multirow{4}{*}{$10^{-4}$} & FI3BBDF(5) & $5.51558 E-5$ & $4.83860 E-2$ \\
& FI3BEBDF(6) & $4.27506 E-5$ & $7.74877 E-2$ \\
& DI2BBDF(2) & $8.89803 E-9$ & $1.17438 E-2$ \\
& DI2BBDF(3) & $1.30124 E-8$ & $1.31578 E-2$ \\
& DI2BBDF(4) & $1.69456 E-8$ & $1.26071 E-2$ \\
\hline \multirow{4}{*}{$10^{-6}$} & FI3BBDF(5) & $5.51803 E-7$ & $5.47768 E+0$ \\
& FI3BEBDF(6) & $4.27924 E-7$ & $7.77643 E+0$ \\
& DI2BBDF(2) & $1.26115 E-11$ & $1.19318 E+0$ \\
& DI2BBDF(3) & $6.27106 E-11$ & $1.33892 E+0$ \\
& DI2BBDF(4) & $1.04222 E-11$ & $1.26146 E+0$ \\
\hline
\end{tabular}

TABle 6: The accuracy for Problem 6.

\begin{tabular}{lccc}
\hline$h$ & Methods & MAXE & TIME \\
\hline \multirow{4}{*}{$10^{-2}$} & FI3BBDF(5) & $2.18555 E-3$ & $2.83084 E-4$ \\
& FI3BEBDF(6) & $1.52719 E-3$ & $4.28500 E-4$ \\
& DI2BBDF(2) & $3.87041 E-5$ & $5.38826 E-5$ \\
& DI2BBDF(3) & $5.47958 E-5$ & $5.31673 E-5$ \\
& DI2BBDF(4) & $7.47696 E-5$ & $6.18877 E-5$ \\
\hline \multirow{4}{*}{$10^{-4}$} & FI3BBDF(5) & $2.29812 E-5$ & $1.48627 E-2$ \\
& FI3BEBDF(6) & $1.78708 E-5$ & $2.32184 E-2$ \\
& DI2BBDF(2) & $4.01638 E-9$ & $3.49712 E-3$ \\
& DI2BBDF(3) & $5.87347 E-9$ & $3.75295 E-3$ \\
& DI2BBDF(4) & $7.64927 E-9$ & $3.64804 E-3$ \\
\hline \multirow{4}{*}{$10^{-6}$} & FI3BBDF(5) & $2.29936 E-7$ & $1.46660 E+0$ \\
& FI3BEBDF(6) & $1.78973 E-7$ & $2.28775 E+0$ \\
& DI2BBDF(2) & $9.90807 E-12$ & $3.38157 E-1$ \\
& DI2BBDF(3) & $3.77716 E-11$ & $3.69837 E-1$ \\
& DI2BBDF(4) & $4.62796 E-12$ & $3.56802 E-1$ \\
\hline
\end{tabular}

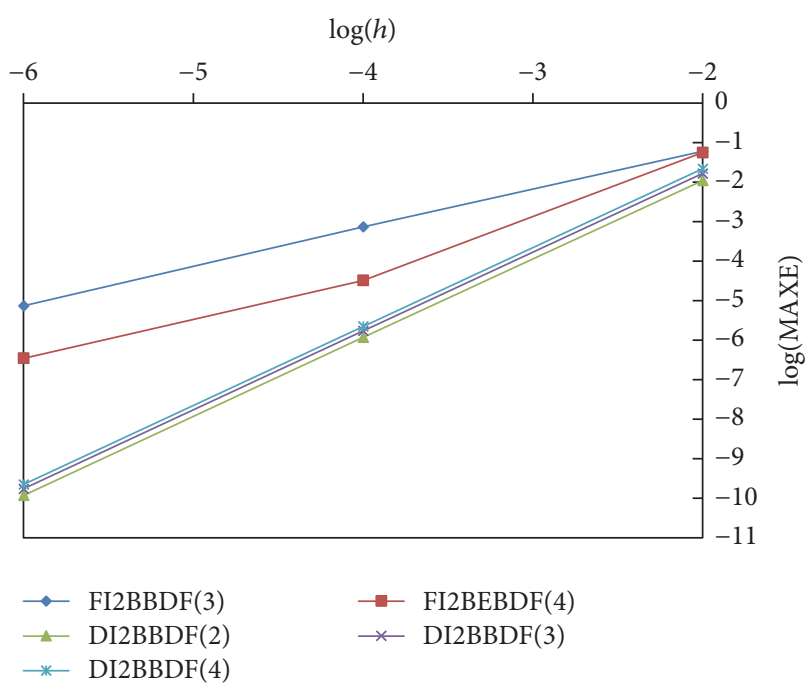

Figure 5: Graph of $\log ($ MAXE) versus $\log (h)$ for Problem 1.

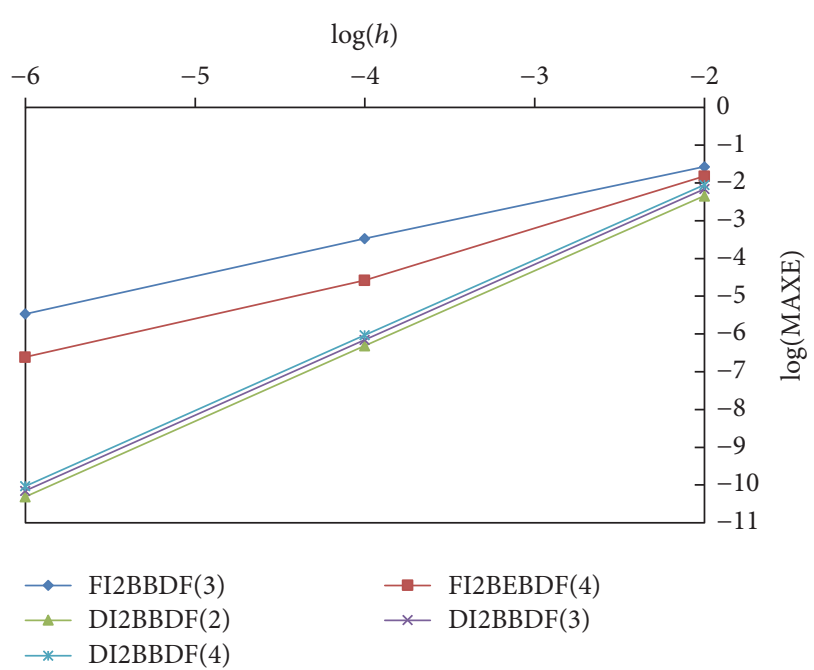

Figure 6: Graph of $\log (\mathrm{MAXE})$ versus $\log (h)$ for Problem 2.

FI3BEBDF(3)" should be changed to "Among the methods of order three, DI2BBDF(3) is more accurate compared with FI2BBDF(3), FI3BBDF(5), FI2BEBDF(4), and FI3BEBDF(6)."

In subsection "Computational Time," the sentence "In Tables 1-2, it can be seen that the execution time taken by $\operatorname{DI} 2 \mathrm{BBDF}(2), \operatorname{DI} 2 \mathrm{BBDF}(3)$, and $\mathrm{DI} 2 \mathrm{BBDF}(4)$ is comparable with that of FI2BBDF(3) and FI2BEBDF(3)" should be changed to "In Tables 1-2, it can be seen that the execution time taken by DI2BBDF(2), DI2BBDF(3), and DI2BBDF(4) is comparable with that of FI2BBDF(3) and FI2BEBDF(4)." In addition, the sentence "However, Tables 3-6 show that the proposed methods compute faster than FI3BBDF(3) and FI3BEBDF(3)" should be changed to "However, Tables 3-6 show that the proposed methods compute faster than FI3BBDF(3) and FI3BEBDF(6)".

The authors apologize to the readers for these errors. 

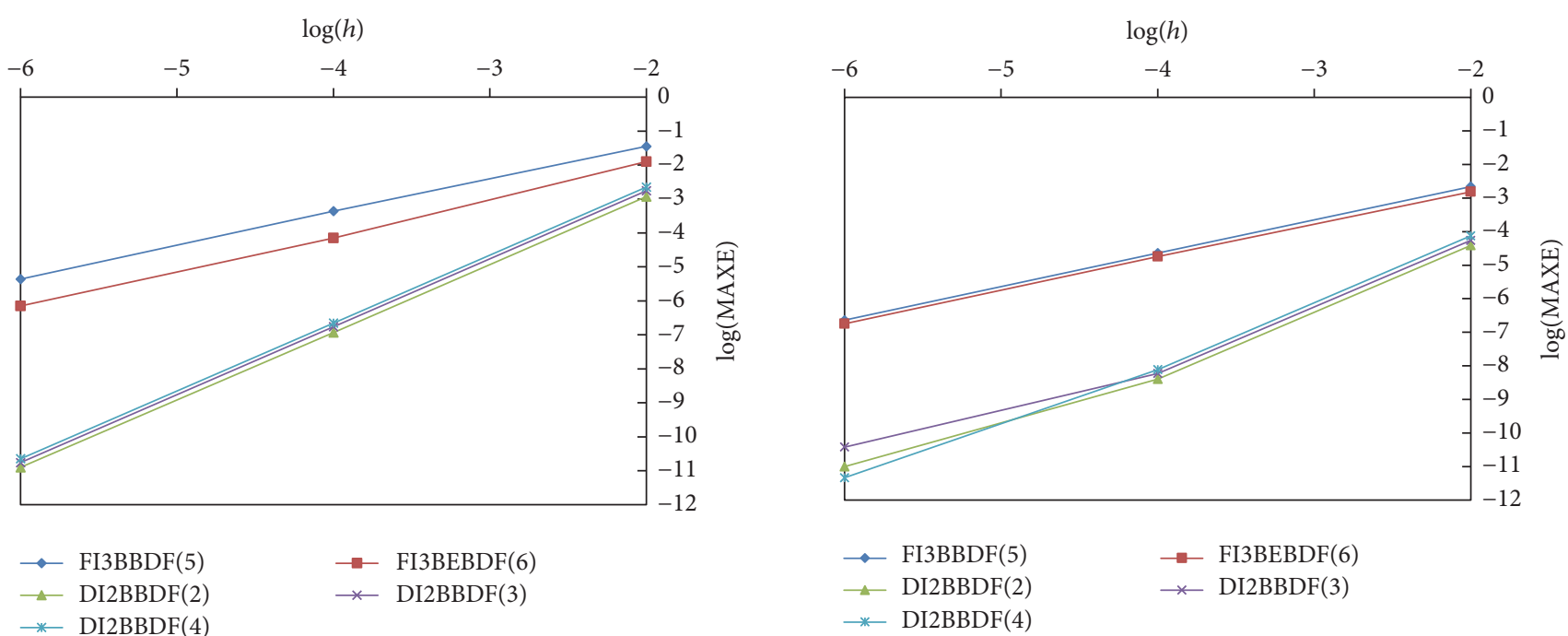

* $\operatorname{DI} 2 \mathrm{BBDF}(4)$

Figure 7: Graph of $\log (\mathrm{MAXE})$ versus $\log (h)$ for Problem 3.

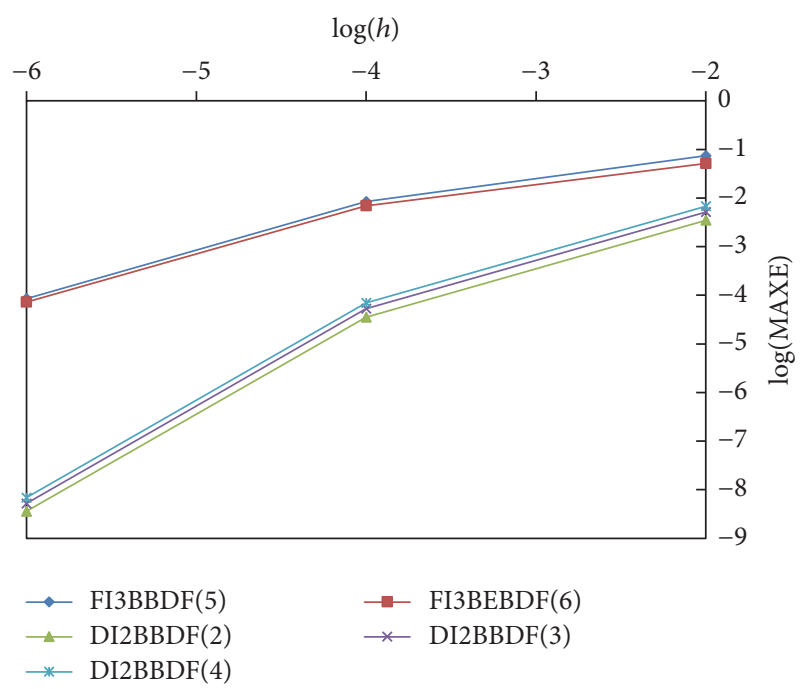

FIGURE 8: Graph of $\log (\mathrm{MAXE})$ versus $\log (h)$ for Problem 4.

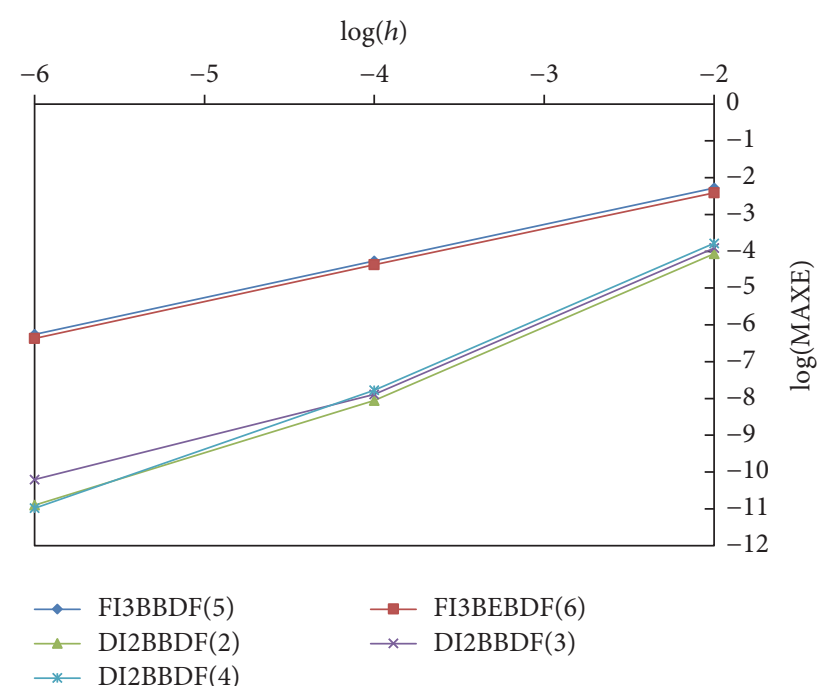

Figure 9: Graph of $\log (\mathrm{MAXE})$ versus $\log (h)$ for Problem 5.

\section{References}

[1] I. S. Zawawi, Z. B. Ibrahim, and K. I. Othman, "Derivation of diagonally implicit block backward differentiation formulas for solving stiff initial value problems," Mathematical Problems in Engineering, vol. 2015, Article ID 179231, 13 pages, 2015. 


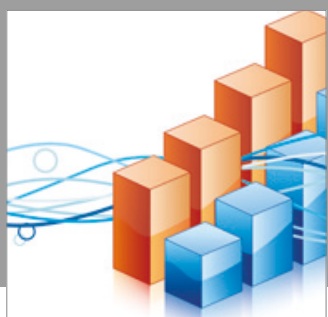

Advances in

Operations Research

vatersals

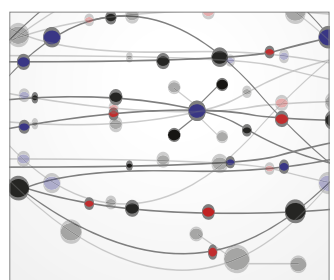

\section{The Scientific} World Journal
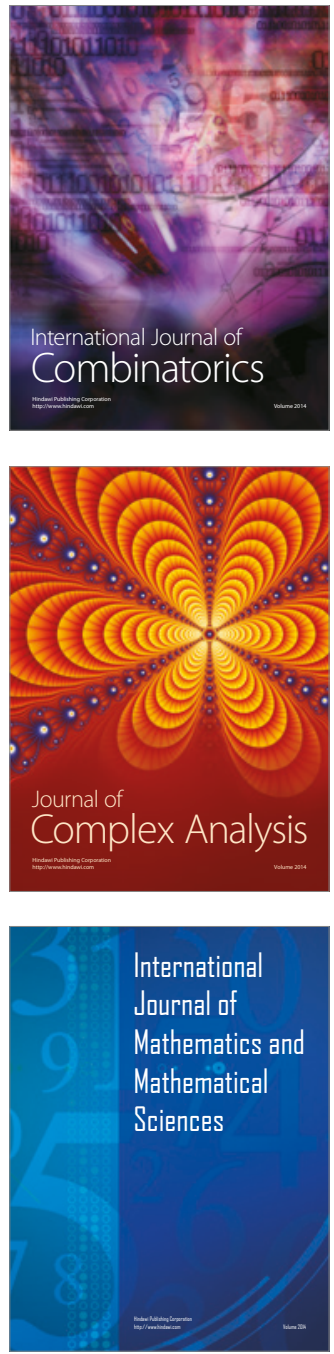
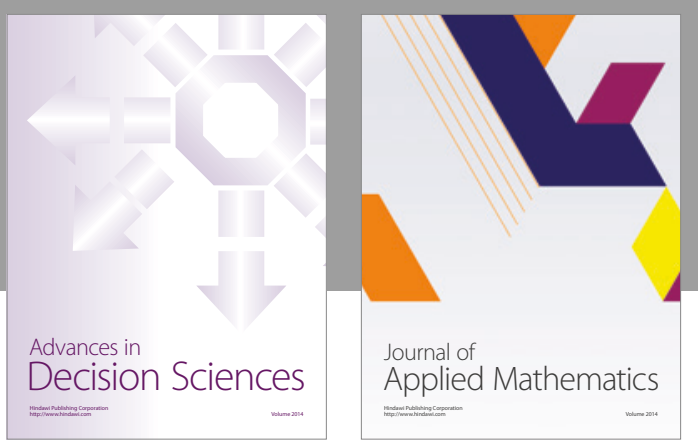

Algebra

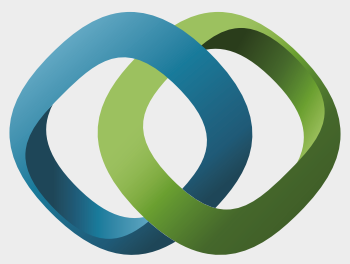

\section{Hindawi}

Submit your manuscripts at

https://www.hindawi.com
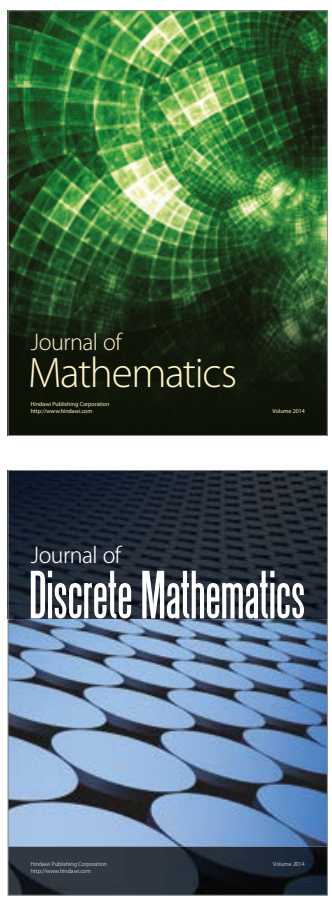

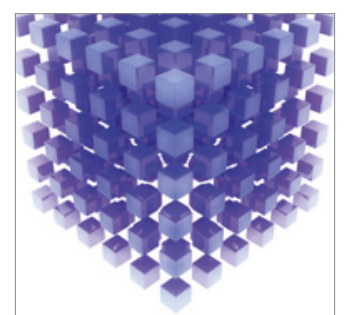

Mathematical Problems in Engineering
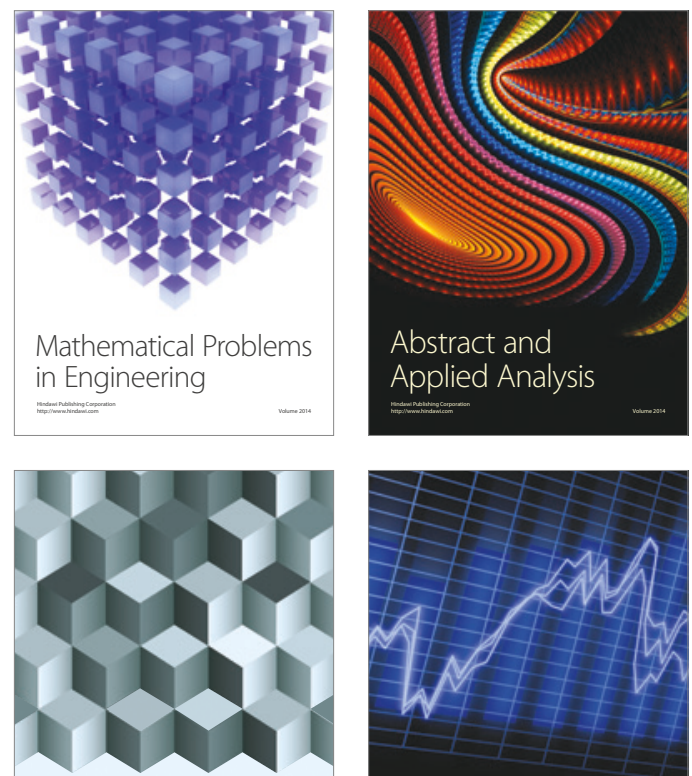

Journal of

Function Spaces

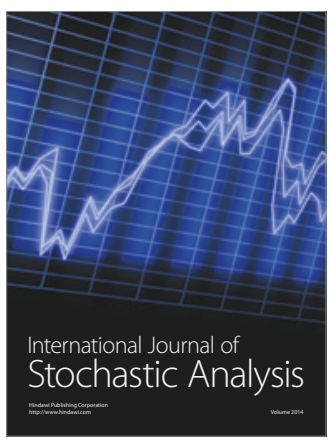

Probability and Statistics
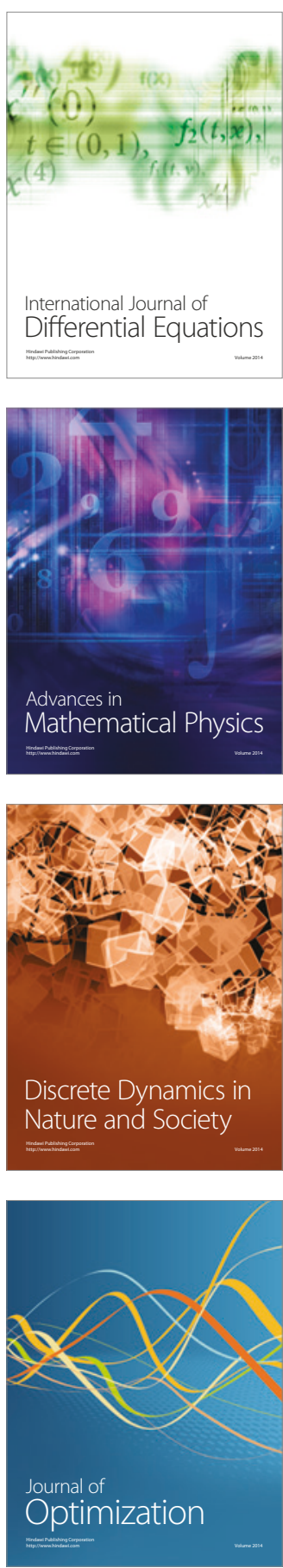